\title{
HIV-related stigma as perceived by HIV-positive individuals in Singapore
}

\author{
Yijun Carol Lin, Jaspal Singh Dhaliwal, Adele Zi Hing Kong, Lai Gwen Chan, Pei Lin Lynnette Tan
}

Tan Tock Seng Hospital, Singapore

\begin{abstract}
Introduction: This analysis of data from a historical cohort of newly-diagnosed HIV patients aimed to quantify illness-related stigma, using the HIV Stigma Scale. At present, there is no quantitative data on HIV-related stigma in the HIV population in Singapore. In order to facilitate future monitoring and evaluation of stigma in the local HIV population, it is important to describe the patterns of, and identify factors associated with HIV-related stigma.
\end{abstract}

Material and methods: The study utilized retrospective data that was collected from August 2010 to May 2013 at the Communicable Disease Centre (CDC) at Tan Tock Seng Hospital, Singapore. Responses to statements of the HIV Stigma Scale from 497 HIV-positive outpatients were analyzed.

Results: Results of analyses indicated that stigma scores did not differ significantly across gender or employment status. However, total stigma scores and stigma scores across the domains of personalized stigma, negative self-image, and public attitudes toward people living with HIV/AIDS, showed significant variation across race. Additionally, singles reported significantly more disclosure stigma than married individuals. In terms of sexual orientation and educational level, personalized stigma and disclosure stigma scores showed significant variations across the groups. In addition, increased age was significantly related to an increase in all stigma scores, except for disclosure stigma, which showed a significant corresponding decrease with the increase in age.

Conclusions: Findings of this study indicate the pervasive nature of HIV-related stigma and highlight certain groups in the population that could benefit more from future implementation of interventions.

HIV AIDS Rev 2017; 16, 3: 176-182 DOI: https://doi.org/10.5114/hivar.2017.70711

Key words: stigma, HIV/AIDS, HIV-related stigma, disclosure, negative self-image.

\section{Introduction}

Social stigma surrounding human immunodeficiency virus (HIV)/acquired immunodeficiency syndrome (AIDS) has garnered considerable research interest in its impact on people living with HIV/AIDS (PLWHA). There is a general consensus that HIV-related stigma poses a major barrier to the control of the HIV pandemic. Fears of stigmatization heighten feelings of denial and the need for conceal-

Address for correspondence: Yijun Carol Lin, Department of Psychological Medicine, Tan Tock Seng Hospital, 11 Jalan Tan Tock Seng, Annex 1 Level 3, 308433 Singapore, Singapore,

phone: +6597701992, e-mail: lin.yijun.carol@gmail.com ment [1-3]. These result in various social and medical repercussions, increase the complexity of managing the disease. Access to HIV screening services and early medical treatment is often delayed [4-7], and PLWHA's opportunities to social support networks and positive interactions with other individuals are limited $[8,9]$. Moreover, stigma perceived by PLWHA often leads to social isolation and internalized shame, thereby increasing their vulnerability to psychopathology $[2,10-12]$, which may interfere with medication
Article history:

Received: 26.01.2017

Received in revised form: 19.05.2017

Accepted: 02.07.2017

Available online: 05.10.2017
International Journal of HIV-Related Problem

HIV \& AIDS

R e vi e w 
adherence and compromise their health status and quality of life $[3,13,14]$.

In Singapore, more than 7,000 residents are living with HIV [15], and early detection of the disease as well as overcoming social stigma, remain key challenges $[5,16]$. To facilitate early detection of HIV, local public hospitals have offered routine opt-out HIV screening for inpatients aged 21 years and above. However, a low acceptance rate of $20 \%$ was reported by Chua and colleagues [16], with the fear of being socially stigmatized cited as one of the primary reasons for declining HIV testing.

At present, there is no quantitative data on HIV-related stigma in the local HIV population. Given the cultural and socioeconomic differences, current international studies may not be generalizable to the local context. Therefore, this study aimed to describe the patterns of self-perceived stigma in a cohort of newly-diagnosed HIV patients, and to identify factors associated with stigma. This would facilitate future monitoring and evaluation of stigma in the local HIV population.

Table 1. Descriptive characteristics of the sample

\begin{tabular}{|c|c|c|}
\hline Factor & $n$ & $\%$ \\
\hline Total & 497 & \\
\hline \multicolumn{3}{|l|}{ Gender } \\
\hline Male & 459 & 92.4 \\
\hline Female & 38 & 7.6 \\
\hline \multicolumn{3}{|l|}{ Marital status } \\
\hline Single & 391 & 78.7 \\
\hline Married & 106 & 21.3 \\
\hline \multicolumn{3}{|l|}{ Employment status } \\
\hline Employed & 309 & 62.2 \\
\hline Unemployed & 188 & 37.8 \\
\hline \multicolumn{3}{|l|}{ Race } \\
\hline Chinese & 360 & 72.4 \\
\hline Malay & 83 & 16.7 \\
\hline Indian & 30 & 6.0 \\
\hline Others & 24 & 4.8 \\
\hline \multicolumn{3}{|l|}{ Sexual orientation } \\
\hline Heterosexuals & 193 & 38.8 \\
\hline $\begin{array}{l}\text { Homosexuals/ } \\
\text { Bisexuals }\end{array}$ & 287 & 57.7 \\
\hline Unspecified & 17 & 3.4 \\
\hline \multicolumn{3}{|l|}{ Educational level } \\
\hline No formal & 9 & 1.8 \\
\hline Primary & 57 & 11.5 \\
\hline Secondary & 143 & 28.8 \\
\hline Tertiary & 285 & 57.3 \\
\hline Unspecified & 3 & 0.6 \\
\hline
\end{tabular}

\section{Material and methods}

\section{Context, study design, and participants}

The Communicable Disease Centre (CDC) at Tan Tock Seng Hospital is the main referral center for HIV treatment in Singapore. All newly-diagnosed HIV-positive outpatients at the CDC are invited to participate in the Psychological Wellness Programme (PWP), which looks into psychological needs of HIV-positive patients. Participation is voluntary and subject to a minimum score of 7 on the Abbreviated Mental Test (AMT), to exclude patients with significant cognitive impairment. Then, eligible patients complete a set of self-administered scales. Care coordinators would score the responses and arrange for referrals to other healthcare professionals as appropriate.

The current study was an analysis of data from a cohort of patients screened from August 2010 to May 2013 as a part of the aforementioned PWP. The use of retrospective data for purposes of this study received approval from the National Healthcare Group Institutional Review Board.

\section{Measures and scoring}

Demographic characteristics such as age, gender, race, sexual orientation, marital status, employment status, and educational level were recorded. Thereafter, patients were assessed for perceptions of HIV-related stigma using the Berger HIV Stigma Scale [17]. This self-reported scale measures four dimensions of stigma: personalized stigma (PS; 18 items), disclosure concerns (DS; 10 items), negative self-image (NSI; 13 items), and public attitudes towards PLWHA (PA; 20 items). Each item is scored on a 4-point Likert scale ( $1=$ strongly disagree, $4=$ strongly agree). As items overlap across domains, there are a total of 40 items in this scale. Items relating to the respective domains of stigma are summed to give a complex score of each subscale, and the total stigma score (TSS) is represented by the sum of these 40 items. Higher scores represent higher levels of stigma.

\section{Statistical analyses}

Basic descriptive statistics were derived to characterize the sample. Correlations, independent $t$-tests, and one-way between-subjects ANOVA with post-hoc analyses were conducted. All analyses were run with a significance threshold of 0.05 .

\section{Results}

A total of $803 \mathrm{HIV}$-positive outpatients were approached for screening, and 506 (63.0\%) consented to be enrolled in the PWP. However, six participants obtained AMT scores that were less than 7 , and three did not complete the stigma scale. They were excluded from analyses, leaving a final sample of 497 participants. Participants in the final sample 


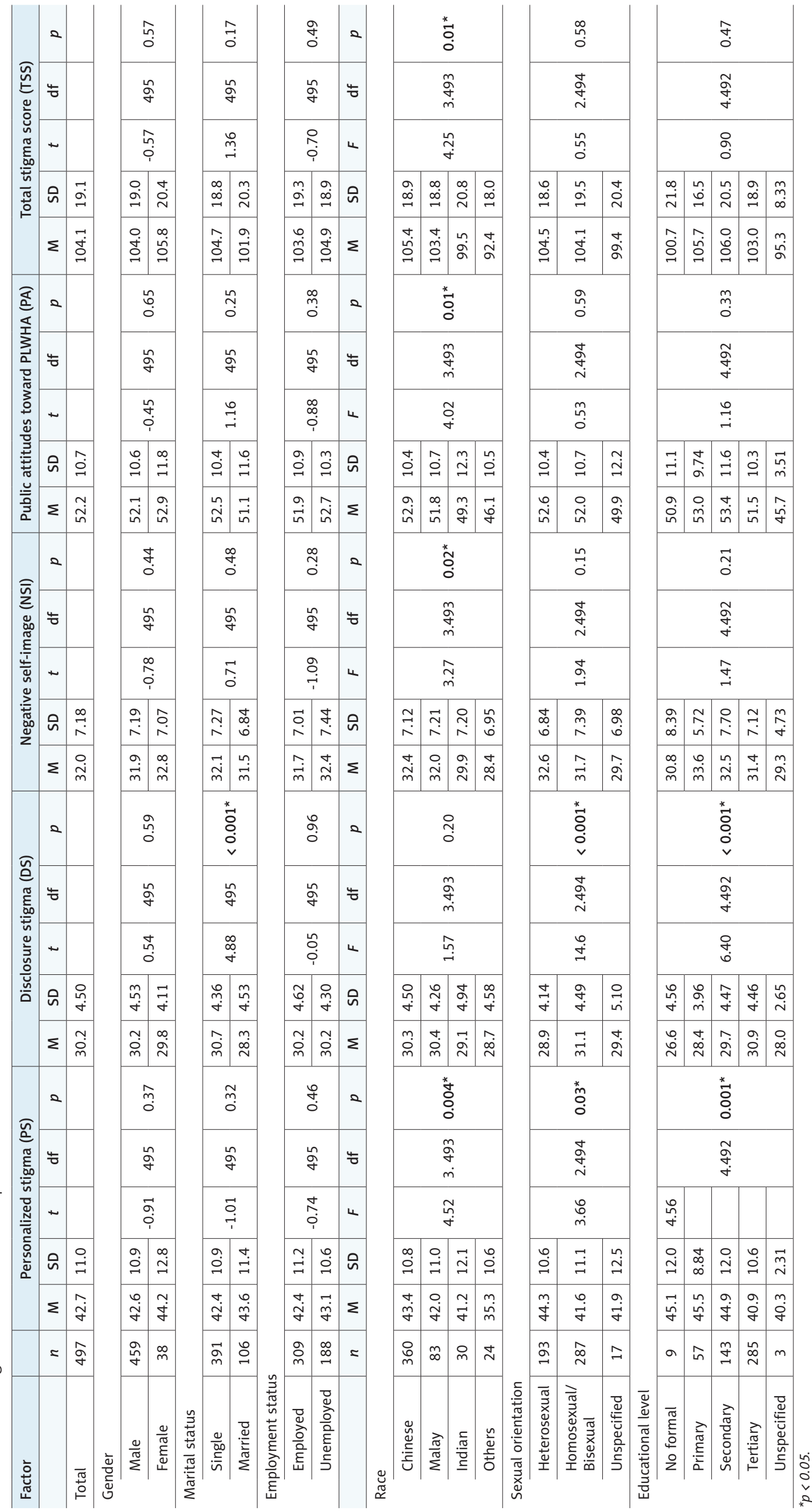


Table 3. Correlation coefficients for age and stigma

\begin{tabular}{l|c|c}
\hline \multirow{2}{*}{} & \multicolumn{2}{|c}{ Entire sample $(n=497)$} \\
\cline { 2 - 3 } & Age & $p$-value \\
\hline Personalized stigma (PS) & 0.214 & $<0.001^{*}$ \\
\hline Disclosure stigma (DS) & -0.163 & $<0.001^{*}$ \\
\hline Negative self-image (NSI) & 0.124 & $0.006^{*}$ \\
\hline $\begin{array}{l}\text { Public attitudes toward } \\
\text { PLWHA (PA) }\end{array}$ & 0.122 & $0.006^{*}$ \\
\hline $\begin{array}{l}\text { Total stigma score (TSS) } \\
{ }^{*} p<0.05 .\end{array}$ & 0.103 & $0.022^{*}$ \\
\hline
\end{tabular}

were aged 17 to 72 years ( $M=38.9$ years, $S D=12.4$ years $)$. A description of the current sample is presented in Table 1. Table 2 displays the mean stigma scores categorized by demographic variables, and the respective statistical test values.

\section{Stigma and gender}

Females had higher stigma ratings across all domains compared to males, with the exception of DS. Likewise, females had higher TSS than males. However, these differences in stigma scores were non-significant.

\section{Stigma and marital status}

Patients who were single reported significantly higher levels of DS compared to married patients, whilst the differences in PS, NSI, PA, and TSS were non-significant. However, as same-sex marriage is illegal in Singapore, we conducted separate analyses on data provided by only heterosexual individuals to rule out potential confounding effects of sexual orientation. These analyses showed that single heterosexual patients $(n=103)$ reported higher stigma scores within all domains, as well as TSS, compared to those who were married $(n=90)$. However, these differences were non-significant $\left(t_{\mathrm{PS}(191)}=1.12, t_{\mathrm{DS}(191)}=1.79, t_{\mathrm{PA}(191)}=1.78, t_{\mathrm{TSS}(191)}=1.97\right.$; $p>0.05)$, with the exception of NSI. Single patients reported significantly higher NSI scores $(\mathrm{M}=33.6, \mathrm{SD}=6.65)$ than those who were married $(\mathrm{M}=31.6, \mathrm{SD}=6.93 ; p=0.043)$.

\section{Stigma and employment status}

Unemployed individuals reported greater stigma across the various domains when compared to those who were employed. Unemployed participants also reported greater TSS than those who were employed. However, these differences in stigma scores were non-significant.

\section{Stigma and race}

Chinese reported the highest levels of stigma, followed by Malays, Indians, and patients of other races, hereinafter referred to as Others. PS, NSI, and PA differed significantly across race. TSS also differed significantly across race. Chinese reported significantly higher levels of PS $(p=0.002)$, NSI $(p=0.038)$, PA $(p=0.012)$, and TSS $(p=0.007)$ than Others. Additionally, Malays reported significantly higher levels of PS compared to Others $(p=0.040)$. Race did not appear to have a significant effect on DS.

\section{Stigma and sexual orientation}

Sexual orientation had a significant effect on PS and DS, but not on PA and NSI. Heterosexuals reported significantly higher PS $(p=0.020)$ and significantly lower DS $(p<0.001)$ than homosexuals/bisexuals. Sexual orientation did not appear to have a significant effect on TSS.

\section{Stigma and educational level}

The educational level of patients had a significant effect on PS and DS, but not on NSI and PA. Patients with a tertiary education reported significantly less PS than those with primary $(p=0.028)$ or secondary education $(p=0.003)$, and significantly more DS than those who received no formal education $(p=0.030)$ or primary education $(p=0.001)$. Total stigma score did not appear to vary significantly between patients with different educational levels.

\section{Stigma and age}

Table 3 outlines the correlation coefficients for age and stigma. Stigma scores across all domains, as well as TSS, were significantly related to age. All the stigma scores increased with age, with the exception of DS.

\section{Discussion}

To our knowledge, this is the first study to shed light on HIV-related stigma in the Singapore HIV population. From our findings, HIV-related stigma appears to be a concern in the Singapore population, with mean HIV-stigma scores across the various domains being generally higher than that reported by PLWHA in Sweden [18] and India [19]. In addition, TSS levels in the current study were higher than that reported by PLWHA in India and comparable to that reported by PLWHA in China [20].

Furthermore, HIV-related stigma does not appear to be restricted to only certain demographic groups within the Singapore community. PLWHA across the society continue to perceive stigma against them, ranging from fears of being discredited by others because of them being or disclosing that they are HIV-positive (PS, DS, PA), to shame and guilt (NSI). These indicate that current measures, such as those by the Health Promotion Board, Singapore, including public education about the illness, as well as community campaigns to raise awareness of HIV transmission pathways and correct misconceptions, are insufficient in addressing HIV-related stigma in Singapore. These also corroborate 
a recent report, which stated that PLWHA in various countries remain highly stigmatized, and emphasized the need to intensify global action to reduce HIV-related stigma and discrimination [21].

\section{Stigma and gender}

In the current study, females perceived higher levels of PS, NSI, PA, and TSS, and lower levels of DS than males but these were non-significant, suggesting little or no involvement of gender differences in HIV-related stigma. This is inconsistent with studies conducted in Nigeria and Canada, which found that women experience significantly higher levels of HIV-related stigma than men [22, 23]. It is proposed that the small number of females in the current sample could have accounted for these findings.

\section{Stigma and marital status}

Results of the current study indicate that single PLWHA perceive significantly more DS than married PLWHA, but the same does not apply to PS, NSI, PA, and TSS. Nonetheless, these findings should be interpreted with caution, as sexual orientation could be a confounder. When separate analyses were conducted on data provided by only heterosexual individuals, NSI scores differed significantly between single and married patients, but DS scores no longer did so. The loss in significant difference between single and married PLWHA for DS is not unexpected. There is an evidence suggesting that disclosure concerns are inevitable for individuals suffering from chronic illness and PLWHA, whether single or married, are no exception [7,21]. Disclosure is necessary to obtain social support [24], and each new disclosure would risk a stigmatizing response, regardless of how well past disclosure experiences have been [17].

\section{Stigma and employment status}

In the current sample, stigma scores did not differ significantly with employment status. This finding is inconsistent with that of the study conducted by Vanable et al. [3], which found that HIV-related stigma was significantly higher among unemployed participants. A plausible explanation for this could be that seropositive individuals, even while employed, might not perceive job security or be meaningfully engaged in their work. A brief evidence has outlined how HIV-related stigma remains an obstacle to PLWHA in terms of not only securing, but retaining employment and procuring advancement opportunities at work [25]. Further, PLWHA in Singapore have expressed the fear of discrimination and loss of employment if their employers were to know of their seropositive status [26] with only one out of 82 PLWHA in Singapore informing their employers about their medical condition.

Although the Singapore National Employers Federation have called for fair employment practices and discourage employers against termination of an employee's services sim- ply because of their seropositive status, Singapore has yet to implement a specific employment legislation regarding HIV/ AIDS at the workplace [26]. Employers can still opt to dismiss an employee without having to provide a reason, as long as they serve adequate notice. Hence, as much as unemployed PLWHA in Singapore may have difficulties securing employment as they are worried that they would be required to undergo comprehensive health screening or declare their health status prior to employment, employed PLWHA may also feel that their condition limits their opportunities at work and therefore perceive similar levels of HIV-related stigma.

\section{Stigma and race}

In the present study, race appeared to have a significant impact on stigma, in that Chinese had reported perceiving significantly higher PS, NSI, PA, and TSS than Others, and Malays had reported significantly higher PS than Others. These results are similar to that of other studies. In a study conducted among PLWHA in Canada, Asians have been found to experience higher levels of HIV-related stigma compared to Caucasian individuals [23]. Taken together, these findings could be indicative of ethnic and cultural differences that influence HIV-related stigma.

\section{Stigma and sexual orientation}

Results of the present study indicate that homosexuals/ bisexuals appear to suffer from significantly less PS than heterosexuals. A possible explanation could be that homosexuals/bisexuals have access to a larger network of like-minded individuals with similar experiences, who provide support and understanding [2].

In addition, heterosexuals in the current study perceive significantly less DS than homosexuals/bisexuals. As HIV is associated with sexual behavior, which is often linked with strong religious or cultural influence, PLWHA are frequently stigmatized as a result of their sexual preferences [12], and experience judgment to have engaged in behavior that their community might perceive as inappropriate. Therefore, homosexuals/bisexuals may face more fears of disclosure than heterosexuals as they not only have to worry about the disclosure of their serostatus, but also their sexual orientation, which they might have kept hidden [2, 11]. This could be particularly relevant in Singapore, which remains largely conservative and not entirely tolerant of homosexual/bisexual orientation [27], since same-sex marriage and homosexual sex are still legally prohibited.

\section{Stigma and educational level}

In the present study, patients with a tertiary education reported significantly less PS than patients with only a primary or secondary education. Additionally, seropositive individuals in Singapore who were more highly educated, reported significantly higher levels of DS. These results show mixed 
support for previous research, which found that those with more education perceived lower levels of stigma [23, 28]. Results obtained for PS are in keeping with previous studies, and suggest that the more highly-educated PLWHA show better understanding of their condition. However, our study shows that DS scores were not lower among those with higher levels of education and were directly proportional to educational level. There may be several reasons for this, including higher expectations by the more highly-educated and their peer groups that they should have been more aware of potential risks of transmission of HIV, as well as higher perceived stakes and societal pressures when considering disclosure of their seropositive status. A separate study conducted in China, utilizing the same HIV-related stigma scale, shows support for these findings, in that individuals with a higher education level who were infected with HIV through a route other than blood transfusions, reported higher levels of perceived HIV-related stigma [20].

\section{Stigma and age}

Older PLWHA in the current study perceive higher levels of PS, NSI, PA, and TSS than younger PLWHA. This is largely in line with existing research, which has found that older PLWHA experience increased levels of stigma as opposed to their younger counterparts, due to reasons like ageism that add to and exacerbate HIV-related stigma [29].

Age was found to be consistently related to disclosure concerns, in that increasing age was correlated with lower disclosure concerns. This could be due to more internal resources being available with increased age, such as better coping methods and higher income or job stability [30]. In addition, findings of the current study could be due to the demographic characteristics of the population. Older males and females in Singapore were mostly infected with HIV via the heterosexual route of transmission as compared to homosexual/bisexual, or other forms of transmission from 2010 to 2013 [31]. Another study conducted over the span of 2006 and 2011 also found that younger HIV patients at the CDC in Singapore were mostly homosexual, whilst the older HIV patients were mostly heterosexual [32]. Since older PLWHA mostly comprise of heterosexuals, and prior findings of the current study indicate that heterosexuals report lower levels of DS, these could have explained the finding that the older PLWHA had less disclosure concerns.

\section{Limitations of study and concluding comments}

Participation in the PWP was optional. Patients who declined participation might have encountered more negative experiences of stigmatization, thus introducing the possibility of selection bias to the study. However, it was not possible to analyze these potential differences as data was not collected from patients who declined participation in the PWP. Further, as there has yet to be a clear and consistent definition of HIV-related stigma across literature, the current measure of HIV-related stigma suffers from limited clinical utility.

Nevertheless, the authors believe that the study sample is relatively extensive and closely corresponds to the local HIV population in terms of gender and ethnic composition $[16,31]$, espousing generalizability of the findings, at least in the local context. Additionally, this paper is a noteworthy contribution to the body of empirical research exploring perceived stigma by PLWHA. It bridges the knowledge gap by quantifying HIV-related stigma using the HIV stigma scale, offering a more objective profile of perceived stigma. The resulting data opens up important avenues for future research, and aids the development of more meaningful strategies to overcome HIV-related stigma. Subsequent studies should be taken to delineate the trajectory of perceived stigma over time, to understand how HIV-related stigma could affect the progression of the illness, as well as clinical data such as treatment adherence in Singapore. Future studies could also explore if there are confounding variables such as psychiatric or medical comorbidity, as well as patients' reasons for seeking a HIV test [33], to provide a more comprehensive understanding of HIV-related stigma.

Considering the negative impact of HIV-related stigma outlined in literature, the findings of this study clearly highlight the need to improve the wellbeing of patients by trying to not only reduce the occurrence of HIV-related stigma within society, but also to tailor interventions to help patients to cope with this stigma. More importantly, HIV-related stigma in Singapore is relatively higher than in other countries. Given that such high levels of HIV-related stigma were reported by individuals sampled from a treatment-seeking population, nation-wide interventions should also be implemented to reach out to individuals who may experience even more negative experiences of stigmatization, and thus opt to default treatment. In conclusion, HIV-related stigma remains a concern in Singapore and more efforts and resources should be channeled into mitigating the levels of this stigma.

\section{Conflict of interest}

The author's declared no potential conflicts of interest with respect to the research, authorship, and/or publication of this article.

\section{References}

1. Clark HJ, Lindner G, Armistead L, et al. Stigma, disclosure, and psychological functioning among HIV-infected and non-infected African-American women. Women Health 2003; 38: 57-71.

2. Logie CH, James L, Tharao W, et al. HIV, gender, race, sexual orientation, and sex work: A qualitative study of intersectional stigma experienced by HIV-positive women in Ontario, Canada. PLoS Med 2011; 8: e1001124.

3. Vanable PA, Carey MP, Blair DC, et al. Impact of HIV-related stigma on health behaviors and psychological adjustment among HIV-positive men and women. AIDS Behav 2006; 10: 473-482.

4. Monjok E, Smesny A, Essien EJ. HIV/AIDS-related stigma and discrimination in Nigeria: Review of research studies and future directions for prevention strategies. Afr J Reprod Health 2009; 13: 21-35. 
5. Ng DH. Into the shadow: A reflection on the stigma of human immunodeficiency virus (HIV) in Singapore. Ann Acad Med Singapore 2012; 41: 625-627.

6. Odimegwu C, Adedini SA, Ononokpono DN. HIV/AIDS stigma and utilization of voluntary counselling and testing in Nigeria. BMC Public Health 2013; 13: 465-465.

7. Olalekan AW, Akintunde AR, Olatunji MV. Perception of societal stigma and discrimination towards people living with HIV/AIDS in Lagos, Nigeria: A qualitative study. Mater Sociomed 2014; 26: 191-194.

8. Larios SE, Davis JN, Gallo LC, et al. Concerns about stigma, social support and quality of life in low-income HIV-positive Hispanics. Ethn Dis 2009; 19: 65-70.

9. Varas-Díaz N, Serrano-García I, Toro-Alfonso J. AIDS-related stigma and social interaction: Puerto Ricans living with HIV/ AIDS. Qual Health Res 2005; 15: 169-187.

10. Grov C, Golub SA, Parsons JT, et al. Loneliness and HIV-related stigma explain depression among older HIV-positive adults. AIDS Care 2010; 22: 630-639.

11. Kartikeyan S, Bharmal RN, Tiwari RP, et al. HIV-related psychological disorders. In: HIV and AIDS: Basic elements and priorities. Springer Netherlands, Dordrecht 2007; pp. 177-181.

12. Nachega JB, Morroni C, Zuniga JM, et al. HIV-related stigma, isolation, discrimination, and serostatus disclosure: A global survey of 2,035 HIV-infected adults. J Int Assoc Phys AIDS Care 2012; 11: $172-178$.

13. Andrinopoulos K, Clum G, Murphy DA, et al. Adolescent Medicine Trials Network for HIV/AIDS Interventions. Health related quality of life and psychosocial correlates among HIV-infected adolescent and young adult women in the US. AIDS Educ Prev 2011; 23: 367-381.

14. Ware NC, Wyatt MA, Tugenberg T. Social relationships, stigma and adherence to antiretroviral therapy for HIV/AIDS. AIDS Care 2006; 18: 904-910.

15. Ministry of Health, Singapore. Update on the HIV/AIDS situation in Singapore 2015 (Jun 2016). Ministry of Health, Singapore. Retrieved from: https://www.moh.gov.sg/content/moh_web/home/ statistics/infectiousDiseasesStatistics/HIV_Stats/update-on-the -hiv-aids-situation-in-singapore-20141.html.

16. Chua AC, Leo YS, Cavailler P, et al. Opt-out of voluntary HIV testing: A Singapore hospital's experience. PLoS One 2012; 7: e34663.

17. Berger BE, Ferrans CE, Lashley FR. Measuring stigma in people with HIV: Psychometric assessment of the HIV stigma scale. Res Nurs Health 2001; 24: 518-529.

18. Lindberg MH, Wettergren L, Wiklander M, et al. Psychometric evaluation of the HIV stigma scale in a Swedish context. PLoS One 2014; 9: e114867.

19. Yakhmi S, Singh SB, Kaur B, et al. Study of HIV-related stigma in people living with HIV/AIDS (PLHA): Role of gender differences. Indian J Sci Res 2014; 5: 35-39.

20. Li Z, Sheng Y. Investigation of perceived stigma among people living with human immunodeficiency virus/acquired immune deficiency syndrome in Henan province, China. Int J Nurs Sci 2014; 1 : 385-388.

21. Sidibé M, Goosby EP. Global action to reduce HIV stigma and discrimination. J Int AIDS Soc 2013; 16 (SI): 18893.

22. Kazeem OT. The relation between psychodemographic factors and perceived stigmatisation among people living with HIV/AIDS in Ibadan, Nigeria: A cross-sectional study. Lancet 2013; 382 (S2): S9.

23. Loutfy MR, Logie $\mathrm{CH}$, Zhang Y, et al. Gender and ethnicity differences in HIV-related stigma experienced by people living with HIV in Ontario, Canada. PLoS One 2012; 7: e48168.

24. Stutterheim SE, Bos AER, Pryor JB, et al. Psychological and social correlates of HIV status disclosure: The significance of stigma visibility. AIDS Educ Prev 2011; 23: 382-392.

25. Global Network of People Living with HIV, International Labor Organization Programme on HIV/AIDS and the World of Work,
\& The People Living with HIV Stigma Index. Evidence brief: Stigma and discrimination at work. Findings from the People Living with HIV Stigma Index. 2012. Amsterdam, The Netherlands: Global Network of People Living with HIV (GNP+). Retrieved from http://www.ilo.org/wcmsp5/groups/public/@ed_protect/@protrav/ @ilo_aids/documents/publication/wcms_185808.pdf.

26. Health Promotion Board, \& Singapore National Employers Federation. Guidelines on managing HIV/AIDS at the workplace. 2012. Singapore: Health Promotion Board. Retrieved from http:// www.snef.org,sg/TempDocs/AA/files/SNEF-site-upload/whs/ hivguidelines.pdf.

27. Wong SY. Singapore not ready for same-sex marriage as society is still conservative: PM Lee. The Straits Times, Singapore 2015. Retrieved from: http://www.straitstimes.com/news/singapore/more-singapore-stories/story/singapore-not-ready-same-sex-marriage-society-still-cons.

28. Shacham E, Rosenburg N, Önen NF, et al. Persistent HIV-related stigma among an outpatient US clinic population. Int J STD AIDS 2015; 26: 243-250.

29. Sharp M. Double stigma. In: HIV and aging: Growing older with the epidemic. Cahill S, Schaefer N, Guidry JA (eds.). Gay Men's Health Crisis, Inc., New York 2010; pp. 8-9. Retrieved from: http:// www.gmhc.org/files/editor/file/a_pa_aging10_emb2.pdf.

30. Logie C, Gadalla TM. Meta-analysis of health and demographic correlates of stigma towards people living with HIV. AIDS Care 2009; 21: 742-753.

31. Ministry of Health, Singapore. Update on the HIV/AIDS situation in Singapore 2013. Ministry of Health, Singapore. Retrieved from: http://www.moh.gov.sg/content/moh_web/home/statistics/ infectiousDiseasesStatistics/HIV_Stats/update-on-the-hiv-aids-situation-in-singapore-20130.html.

32. Lee LK, Seinn OPP, Ng OT, et al. Older age at initial presentation to human immunodeficiency virus (HIV) care and treatment at the Communicable Disease Centre (CDC) in Singapore, 2006 to 2011. Ann Acad Med Singapore 2012; 41: 577-580.

33. Fido NN, Aman M, Brihnu Z. HIV stigma and associated factors among antiretroviral treatment clients in Jimma Town, Southwest Ethiopia. HIV AIDS (Auckl) 2016; 8: 183-193. 